\title{
Comparison of Hysterosalpingography with Saline Contrast Transvaginal Salpingography for Evaluation of Tubal Patency of Patients with Infertility
}

\author{
Debasish Dey ${ }^{1}$, Amit Kumar Das², Mali Nandi ${ }^{3}$ \\ 1,3 Department of Radiodiagnosis, Institute of Post Graduate Medical Education \& Research, Kolkata, India. \\ ${ }^{2}$ Department of Radiodiagnosis, R.G. Kar Medical College, Khudiram Bose Sarani, Kolkata, India.
}

\section{ABSTRACT}

\section{BACKGROUND}

Infertility is an important problem faced by about $15 \%$ of couples. Out of many factors, tubal pathology is a significant cause in females. Assessments of tubal patency by hysterosalpingography is used more often in the investigation of infertility. It is a non-invasive, cheap outdoor procedure, without radiation hazards and untoward reactions. In this study both the procedures were compared to assess, their effectiveness in determining the tubal patency in infertility.

\section{METHODS}

This analytical and interventional study was conducted among fifty patients attending the gynaecology \& obstetrics outpatient department of IPGMER and SSKM Hospital. Patients in the reproductive age group with primary or secondary infertility were included in the study. Uterine bleeding, lower genital tract infection, and pelvic inflammatory diseases were the exclusion criteria. Hysterosalpingography was done using fluoroscopic control image intensifier and sonosalpingography was done using transvaginal salpingography (TVS) probe 5 - $10 \mathrm{MHz} / 4$ - $9 \mathrm{MHz}$. Findings regarding tubal patency by hysterosalpingography and TVS were compared.

\section{RESULTS}

Most patients belonged to the age group of $26-30$ yrs. (36\%). 23 patients (46\%) had a body mass index (BMI) of more than 25. Biochemical studies showed that majority of women $(\mathrm{n}=23)$ had normal endocrine profile. Transvaginal sonosalpingography had $95.12 \%$ sensitivity, $88.89 \%$ specificity, $97.5 \%$ positive predictive value and $80 \%$ negative predictive value in comparison to hysterosalpingography in the assessment of tubal patency. TVS had Kappa statistical value of 0.805 (strong agreement).

\section{CONCLUSIONS}

Hysterosalpingography is generally regarded as the definitive test for evaluation of tubal factors of infertility; but it requires radiation exposure and is more painful. Transvaginal sonosalpingography had Kappa statistical value of 0.805 (strong agreement) indicating that it can used as an alternative to hysterosalpingography.

\section{KEY WORDS}

Hysterosalpingography, Sonosalpingography, Infertility, Transvaginal Ultrasound
Corresponding Author: Dr. Amit Kumar Das, Department of Radiodiagnosis, R.G. Kar Medical College, 1, Khudiram Bose Sarani Kolkata-700004, India.

E-mail: dramitkrdas73@gmail.com

DOI: $10.14260 /$ jemds/2021/18

How to Cite This Article:

Dey D, Das AK, Nandi M. Comparison of hysterosalpingography with saline contrast transvaginal salpingography for evaluation of tubal patency of patients with infertility. J Evolution Med Dent Sci 2021;10(02):8892, DOI: $10.14260 / \mathrm{jemds} / 2021 / 18$

Submission 17-07-2020,

Peer Review 04-11-2020

Acceptance 12-11-2020,

Published 11-01-2021.

Copyright (c) 2021 Debasish Dey et al. This is an open access article distributed under Creative Commons Attribution License [Attribution 4.0 International (CC BY 4.0)] 


\section{BACKGROUND}

A simple and precise definition of infertility is, "one year of unprotected coitus without conception". ${ }^{1}$ Infertility is a common and important problem faced by about $15 \%$ of couples. ${ }^{2}$ Infertility may be either primary or secondary. Primary infertility is where there is no prior conception, while secondary infertility is where a prior conception has occurred, although not necessarily a live birth. The process of human reproduction begins with fertilization of the ovum by the spermatozoa. This process of fertilization takes place within the fallopian tube. This complex process relies upon the chance of satisfactory ovulation and transport of viable sperm and ova in the reproductive tract and finally passage of the conceptus into the uterus for implantation.

\section{Factors Responsible for Female Infertility ${ }^{3}$}

Out of many factors, tubal pathology is a significant cause of female infertility. Anatomical tubal disease includes tubal obstruction (proximal, mid, distal), while physiological abnormalities are caused by pelvic adhesions due to infection, endometriosis and previous surgery. Assessments of tubal factors are done by insufflation test, hysterosalpingography (HSG), laparoscopic chromopertubation and saline contrast transvaginal sonosalpingography (SCTVSSG). Every method has its own merits and demerits. Hysterosalpingography is a radiological procedure that outlines the uterine cavity and fallopian tubes. It is used most often in the investigation of infertility. In evaluating the efficacy of pelvic saline contrast transvaginal sonosalpingography in the detection of tubal patency, hysterosalpingography is used as the gold standard for the diagnosis. Hysterosalpingography is however associated with some disadvantages, which include patient discomfort, radiation exposure to patient and personnel, and reaction due to contrast medium. Transvaginal sonosalpingography is introduction of fluid - normal saline through Foley catheter into the uterine cavity - which allows excellent evaluation of tubal patency. It is a non-invasive outdoor procedure, cost effective, with no radiation hazards and untoward reactions. Keeping this in mind, all of the selected patients were subjected to both hysterosalpingography and saline contrast transvaginal sonosalpingography as far as possible in the same menstrual cycle. The results of the two procedures were compared to assess, how far saline contrast transvaginal sonosalpingography is effective in determining the tubal patency in primary and secondary infertility.

\section{Objectives}

1. Assessment of tubal patency by hysterosalpingography and saline contrast transvaginal sonosalpingography and compare their findings.

2. To study demographic profile of infertile patients.

\section{METHODS}

This was an analytical and interventional study conducted from $01 / 01 / 2008$ to $30 / 06 / 2009$ among the patients attending the gynaecology \& obstetrics outpatient department of IPGME\&R and SSKM Hospital. Institutional ethics committee approval was obtained from IEC, SSKM Hospital for the study. 50 patients were studied depending upon the incidence of cases in our hospital and $95 \%$ was confidence limit.

\section{Inclusion Criteria}

Any patient in reproductive age group with primary or secondary infertility. Primary infertility was considered when a woman had never conceived before and secondary infertility was considered as the incapability to conceive in a couple who have had at least one successful conception in the past.

\section{Exclusion Criteria}

- Uterine bleeding.

- Lower genital tract infection.

- Pelvic inflammatory diseases including active genital Koch's.

- $\quad$ Allergy to contrast media.

- $\quad$ Suspected genital tract malignancy.

- Male partner with oligospermia (<10 million / ml).

\section{Parameters Studied}

- Free flow of contrast or fluid in single or both tubes by $\mathrm{x}$ ray or sonography.

- Findings of hydrosalpinx, gross deformity, adhesion of tubes with surrounding structures determined by hysterosalpingography or saline contrast transvaginal sonosalpingography.

- Findings of any adnexal pathology e.g. ovarian cyst, chocolate cyst, polycystic ovarian disease by transvaginal sonosalpingography.

- Abnormal uterine findings including fusion anomalies, $\mathrm{T}$ shaped uterus, fibroid, endometrial polyp and intrauterine synechiae.

\section{Study Tools}

- Fluoroscopic control image intensifier

- $500 \mathrm{~mA}$ x-ray machine with I.I. TV (Siemens)

- $\quad 500 \mathrm{~mA}$ x-ray machine with I.I. TV (ME x-ray)

- $\quad 800 \mathrm{~mA}$ x-ray machine with I.I. TV (Siemens)

Transvaginal sonosalpingography was done by USG machine Toshiba made model Xario using TVS probe 5 - 10 $\mathrm{MHz}$ and Siemens made model Acuson Antares using TVS probe 4 - $9 \mathrm{MHz}$.

\section{Procedure of Saline Contrast Sonosalpingogram}

Patients for TVS were scheduled on day 9 of menstrual cycle. After detailed history and clinical examination, patient was explained the procedure and informed consent obtained. Using strict aseptic precautions, a no. 8 Foley catheter was inserted into uterus with the help of Cusco's speculum and the catheter bulb was gently inflated with $2-3 \mathrm{ml}$ saline to prevent 
retrograde spillage and keep the catheter in place. Speculum was removed and around $10 \mathrm{ml}$ of normal saline was instilled slowly into uterine cavity through the catheter while continuously monitoring by transvaginal ultrasound catheter. Flow of saline in endometrial cavity, fallopian tubes and its collection in pelvis was observed and recorded. Presence of free flow with spillage of saline was considered as patency of tubes. Interruption in flow, non-visualisation in flow though tubes or formation of hydrosalpinx in some part of tubes were considered as tubal blockage.

\section{Procedure of Hysterosalpingography}

The procedure was carried out on the 10th day of the menstrual cycle. The procedure was explained to the patient and informed consent obtained.

The patient was reassured and asked to empty her bladder before the procedure. After positioning on radiographic table with the hips flexed and the vulva exposed, a quick per vaginal examination was done. Perineum was painted with Iodine and draped. Speculum was inserted and the anterior lip of the cervix was held by vulsellum forceps and any visible cervical mucus removed. Next, Leech Wilkinson cannula was filled with the water-soluble contrast material to flush out the air. Cannula was then inserted into the external os under direct vision. The speculum was then removed, and the patient's legs were extended. With fluoroscopic control, $10 \mathrm{ml}$ of contrast was pushed. Spot radiographs were taken to visualise the spill and another radiograph taken 5 min later to visualise the free dispersion of contrast in the pelvic peritoneal cavity. The initial radiograph shows the uterine cavity and fallopian tubes filled with contrast. The subsequent radiograph shows the peritoneal spillage if the tubes are patent. Once the radiographs were found to be satisfactory, the cannula was removed, the vagina cleaned, and the patient was kept under observation for half an hour.

\section{Statistical Analysis}

Descriptive statistics were used to measure the frequencies of different findings in this research. StatCalc software was used to tabulate the findings.

\section{RESULTS}

\begin{tabular}{|cccccc|}
\hline $\begin{array}{c}\text { Age } \\
\text { (Years) }\end{array}$ & Number & Percentage & $\begin{array}{c}\text { Age at } \\
\text { Marriage } \\
\text { (Years) }\end{array}$ & Number & Percentage \\
$\leq 20$ & 5 & 10 & $\leq 20$ & 19 & 38 \\
$21-25$ & 13 & 26 & $21-25$ & 20 & 40 \\
$26-30$ & 18 & 36 & $26-30$ & 10 & 20 \\
$31-35$ & 10 & 20 & $31-35$ & 1 & 2 \\
$>35$ & 4 & 8 & $>35$ & 0 & 0 \\
\hline \multicolumn{5}{c}{ Table 1. Distribution of Patients According to Their } \\
Age and Duration of Marriage \\
\hline
\end{tabular}

In the above table we have tried to demonstrate the relative distribution of the patient, according to their age, it is evident that most patients belonged to age group of $26-30$ yrs. (36\%). Largest group of patients (14) were between age group of $30-40$ years (28\%). Most of the infertile patients were aged between 21 - 25 years ( $40 \%$ ) at marriage.

\begin{tabular}{|ccc|}
\hline Duration of Marriage & No. of women & Percentage (\%) \\
$<5$ Years & 21 & 42 \\
$5-10$ years & 25 & 50 \\
$>$ 10 Years & 4 & 8 \\
\hline Table 2. Distribution of Patients According to Duration of Marriage \\
\hline
\end{tabular}

\begin{tabular}{|ccc|}
\hline B.M.I. (Range) & No. of Women & Percentage (\%) \\
$<18.5$ & 2 & 4 \\
$18.5-22.9$ & 23 & 46 \\
$23-24.9$ & 23 & 46 \\
$>25$ & 2 & 4 \\
\hline Table 3. Distribution of Patients According to Body Mass Index \\
\hline $\begin{array}{l}\text { (50 \%) belong to overweight / obese, B.M.I. more than 25. } 46 \% \text { patients fall in the } \\
\text { normal range (18 - 22.9) of B.M.I. }\end{array}$ \\
\hline
\end{tabular}

\begin{tabular}{|ccc|}
\hline Endocrine Status & No. of Women & Percentage (\%) \\
Normal & 26 & 52 \\
Abnormal TSH & 5 & 10 \\
$\uparrow$ PRL & 3 & 6 \\
$\uparrow$ FBS / PPBS & 6 & 12 \\
Altered FSH / LH ratio & 10 & 20 \\
\hline Table 4. Distribution of Patients According to Endocrinal Status \\
\hline
\end{tabular}

Comparison of hysterosalpingography versus saline contrast transvaginal sonosalpingography in assessing tubal patency (irrespective of right or left sided) Kappa statistic for agreement computed for 50 cases.

\begin{tabular}{|c|c|c|c|c|}
\hline & & \multicolumn{2}{|c|}{ Hysterosalpingography } & \multirow{2}{*}{ Total } \\
\hline & & Patent & Block & \\
\hline \multirow{3}{*}{ SCSSG } & Patent & 39 & 1 & 40 \\
\hline & Block & 2 & 8 & 10 \\
\hline & & 41 & 9 & 50 \\
\hline \multicolumn{5}{|c|}{ Tabulat } \\
\hline
\end{tabular}

Kappa 0.805 [Strong agreement]

Saline contrast transvaginal sonosalpingography has

Sensitivity $=95.12 \%$

Specificity $=88.89 \%$

Positive Predictive Value $=0.975$

Negative Predictive Value $=0.8$

\section{DISCUSSION}

Infertility, although not a disease which endangers one's life or impairs one's daily activities, has an immense impact on marital, social and familial harmony. Treatment for infertility is often lengthy, involves multiple visits and investigations and can become expensive for the couple. The first step for treatment of infertility would be to diagnose if there is a specific cause for infertility. A variety of factors may be responsible for causing infertility. For evaluation of the female partner in infertility requires assessment of uterus, tubes and ovaries for abnormalities potentially preventing normal conception. Tubal factors are the most common cause of female infertility in our country. Tubal patency can be assessed with hysterosalpingography, laparoscopy and saline infusion sonosalpingography.

Hysterosalpingogram is still the most widely used outpatient test advised for a diagnostic workup in infertility patients. Hysterosalpingography is a relatively safe procedure which can be performed in an outpatient setting without the use of sedation or anaesthesia. However, it has certain 
disadvantages - it exposes the patient to ionizing radiation, it has risks of contrast reaction, cannulation and contrast injection can be painful, and there can be false positive results in cases of proximal tubal spasm.

With widespread use and easy availability of ultrasonography, saline infusion sonography has emerged as a more patient friendly alternative for hysterosalpingography. It does not involve ionizing radiation, it is less painful, it can be performed within ten to fifteen minutes, there is no danger of contrast reactions, it does not involve any anaesthesia and ultrasound and can be used for diagnosis of other uterine and tubal pathologies as well.

In our study, we included 50 patients, who attended infertility clinic during our study period, in whom we could do all the proper clinical as well as investigation procedures.

We found most of our patients belonged to age group 26 30 years (36\%). It is also significant that the number of infertile patients between the age group 30 - 40 were 14 (28 $\%)$. Mosher in 1997 noted that, in US, overall increase in infertile women from 1982 - 95 was significantly due to older age.

Data also shows that 20 infertile patients ( $40 \%$ ) have their age at marriage between 21 - 25 years. Also, there were a significant number of patients whose age of marriage was below 20 years, $n=19$ (38 \%). R. Rahim \& S. S. Majid ${ }^{4}$ (2004) reported in Pakistan that, $92 \%$ patients, were in age group of 18 - 34 years, this probably reflects early marriage in developing country. Most of the infertile women presenting to the clinic were married for 5 to 10 years, $\mathrm{n}=25$ (50\%).

The body mass index of our study group was noted, whereby 25 women $(50 \%)$ had a body mass index over 25 . Browne \& Browne (1964) reported that sedentary habit led to reduced fertility. Which corresponds to the findings of our study where majority are obese women.

In our study, we found similar results compared to the studies done elsewhere. A study by Malik et al. (2014) found sonosalpingography had a sensitivity of $95.83 \%$ and specificity of $100 \%$ for evaluation of tubal patency. ${ }^{5}$ They concluded that sonosalpingography is a well-tolerated firstline diagnostic method for evaluation of the tubal status and uterine cavity and can be performed at the same time of ultrasound scan in place of hysterosalpingography. Another study by Kulkarni N, (2016) demonstrated that saline contrast sonography is equally sensitive and specific in diagnosis of tubal patency without any statistically significant difference from hysterosalpingography. ${ }^{6}$ A systematic review by Maheux-Lacroix S (2014) investigating sonosalpingography for diagnosis of tubal occlusion in subfertile women studied 30 studies, representing a total of 1551 women and 2740 tubes. They showed pooled estimates of sensitivity and specificity of sonographic hysterosalpingogram were $92 \%$ (95\% CI: 0.82 0.96 ) and $95 \%$ (95 \% CI: 0.90 - 0.97), respectively. For nine studies sono-hysterosalpingography and hysterosalpingography were both compared with laparoscopy which showed sensitivity and specificity of 0.95 (95 \% CI: 0.78 - 0.99) and 0.93 (95 \% CI: 0.89 - 0.96) for sonohysterosalpingography, and 0.94 (95\% CI: $0.74-0.99$ ) and 0.92 (95 \% CI: 0.87 - 0.95) for hysterosalpingography, respectively. They concluded that sonohysterosalpingography is an accurate test for diagnosing tubal occlusion and performs similarly to hysterosalpingography.$^{7}$
In a study of 1153 , saline infusion sonography procedures, adverse side effects were observed in only $8.8 \%$ of cases including pain, vasovagal symptoms, nausea, vomiting, or fever. ${ }^{8}$ Thus, saline sonography is not only an effective, but also a safe procedure with minimal complications or side effects.

In our study, saline contrast transvaginal sonosalpingography has a $95.12 \%$ sensitivity, $88.89 \%$ specificity, $97.5 \%$ positive predictive value and $80 \%$ negative predictive value in comparison to hysterosalpingography in the assessment of tubal patency. Saline contrast transvaginal hysterosalpingogram has Kappa statistical value of 0.805 (strong agreement). These results show that saline contrast transvaginal hysterosalpingogram has a high sensitivity, positive predictive value and strong agreement with hysterosalpingography. Hence, the study shows the saline contrast transvaginal sonosalpingography can be used as an alternative baseline investigation procedure for evaluating tubal factors in infertile women. It is equally efficacious as hysterosalpingography and offers more advantages.

\section{CONCLUSIONS}

Hysterosalpingography is generally regarded as the definitive test for evaluation of tubal factors of infertility; but it requires radiation exposure, has small risk of contrast reaction, and is more painful. Transvaginal sonosalpingography utilising agitated normal saline as a contrast medium is a reliable, simple, well tolerated, less invasive, cost-effective method for assessment of tubal patency in an OPD setting but it is an operator dependent procedure and requires adequate skill and experience of the operator. All the selected 50 patients of infertility were subjected to saline contrast transvaginal sonosalpingography and hysterosalpingography mostly in the same cycle to find out whether saline contrast transvaginal sonosalpingography can be used for assessment of tubal factor patency as an alternative to hysterosalpingography and to compare findings regarding tubal structural defects between the two procedures. We have found that saline contrast transvaginal sonosalpingography has $95.12 \%$ sensitivity, $88.89 \%$ specificity, $97.5 \%$ positive predictive value and $80 \%$ negative predictive value in comparison to hysterosalpingography in the assessment of tubal patency. Saline contrast transvaginal sonosalpingography has Kappa statistical value of 0.805 (strong agreement); that means it is, as efficacious as hysterosalpingography in the assessment of tubal factors in female infertility.

Data sharing statement provided by the authors is available with the full text of this article at jemds.com.

Financial or other competing interests: None.

Disclosure forms provided by the authors are available with the full text of this article at jemds.com.

\section{REFERENCES}

[1] Speroff L, Glass RH, Kase NH. Clinical gynaecologic endocrinology \& infertility. $7^{\text {th }}$ edn. Lippincott Williams and Wilkins 2005: p. 1013-21. 
[2] Berek JS. Novak's Gynecology. 13 $3^{\text {th }}$ edn. Lippincott Williams and Wilkins 2002: p. 927.

[3] Goldman MA. Gynaecology and obstetrics. In: A guide to the $\mathrm{x}$ - ray department. $3^{\text {rd }}$ edn. Bristol: John Wright \& Sons Ltd., 1978: p. 46-9.

[4] Rahim R, Majid SS. Aetiological factors of infertility. Journal of Postgraduate Medical Institute 2004;18(2):166-71.

[5] Malik B, Patil S, Boricha BG, et al. A comparative study of the efficacy of sonosalpingography and hysterosalpingogram to test the tubal patency in all women with primary and secondary infertility. Ultrasound Q 2014;30(2):139-43.
[6] Kulkarni NN, Patel R, Patel NR, et al. Comparative study of sonosalpingography versus hysterosalpingography for tubal patency test. Int J Reprod Contracept Obstet Gynecol 2016;5(10):1-4.

[7] Maheux-Lacroix S, Boutin A, Moore L, et al. Hysterosalpingosonography for diagnosing tubal occlusion in subfertile women: a systematic review with meta - analysis. Hum Reprod 2014;29(5):953-63.

[8] Dessole S, Farina M, Rubattu G, et al. Side effects and complications of sonohysterosalpingography. Fertil Steril 2003;80(3):620-4. 